\title{
EFSUMB COMPASS for Rheumatologists dissemination and implementation - an international survey.
}

\author{
Iustina Janta1, Lene Terslev², Mads Ammitzbøll-Danielsen², Alexandra Kosevoi-Tichie ${ }^{1,3}$, \\ Hilde Berner-Hammer ${ }^{4}$, Esperanza Naredo ${ }^{1}$
}

${ }^{1}$ Department of Rheumatology, Hospital General Universitario Gregorio Marañón, Faculty of Medicine, Complutense University, Madrid, Spain, ${ }^{2}$ Copenhagen Center for Arthritis Research (COPECARE), Center for Rheumatology and Spine Diseases, Rigshospitalet-Glostrup, University of Copenhagen, Denmark, ${ }^{3}$ Department of Rheumatology and Internal Medicine, Sfanta Maria Hospital, Bucharest, Romania, ${ }^{4}$ Department of Rheumatology, Diakonhjemmet Hospital, Oslo, Norway

\begin{abstract}
Aim: The European Federation of Societies for Ultrasound in Medicine and Biology (EFSUMB) competency assessment (COMPASS) for rheumatologists performing musculoskeletal ultrasound (MSUS) was developed and published 2 years ago. It consists of a 3 level competency system. The objective of this study was to evaluate how the EFSUMB COMPASS has been disseminated and implemented and to assess the potential obstacles encountered. Materials and methods: A questionnaire was developed and distributed by e-mail to all rheumatologists certified as EFSUMB level 3. Results: Seventeen (85\%) rheumatologists considered that the EFSUMB COMPASS is useful for training MSUS. The majority of them (17; 85\%) had informed their colleagues or national rheumatology societies about the EFSUMB COMPASS. The most common obstacle encountered for the implementation of the COMPASS was the lack of time for supervision of the trainees $(9 ; 45 \%)$. A total of 83 rheumatologists had been trained and assessed for competency in the three EFSUMB levels. Conclusion: This survey highlights the current status of EFSUMB COMPASS implementation in European countries with an expected increased number of rheumatologists being able to train and assess new trainees. Still, more efforts should be done for a higher implementation of EFSUMB COMPASS across European countries.
\end{abstract}

Keywords: competency assessment, EFSUMB, musculoskeletal ultrasound, rheumatology, training

\section{Introduction}

Musculoskeletal (MS) ultrasound (US) has been increasingly implemented in rheumatology clinical practice. The need for a standardized training in this technique has led to the development of a competency assessment for the rheumatologists who perform MSUS. In 2012 a working group was created under the umbrella of The European Federation of Societies for Ultrasound in Medicine and Biology (EFSUMB), with

Received 06.12.2015 Accepted 14.12.2015

Med Ultrason

2016, Vol. 18, No 1, 42-46

Corresponding author: Iustina Janta, MD

Rheumatology Department,

Hospital General Universitario Gregorio Marañón

Doctor Esquerdo 46,

28007 Madrid, Spain.

E-mail: iustinajanta@yahoo.com the mission of developing a competency assessment system for rheumatologists in MSUS. This competency assessment was based on an already existing EFSUMB competency assessment for musculoskeletal ultrasound in general $[1,2]$, on the recommendations for the curriculum of the European League Against Rheumatism (EULAR) MSUS courses [3] and on a consensus of the working group.

The EFSUMB competency assessment (COMPASS) for rheumatologists [2] consists of a 3 level system with defined theoretical and practical knowledge and skills that should be achieved at each level. The article by Terslev et al describes in detail the development process of this COMPASS for rheumatologists [4].

The EFSUMB COMPASS was published 2 years ago and the objective of this study was to evaluate how it has been disseminated and implemented since 2013 and what potential obstacles for this have been encountered. 


\section{Material and methods}

An English language questionnaire was developed and distributed by e-mail to all rheumatologists certified as EFSUMB level 3 in 2013 (43 rheumatologists from 17 countries). The questionnaire included 12 questions regarding the dissemination and implementation of COMPASS, and the possible limitations encountered in this. Out of the 12 questions, 4 were multiple choice questions, 4 were yes/no questions (which may include justification), 3 were referring to the total number of rheumatologists trained and 1 requested a free text for suggestions to improve the dissemination and implementation of COMPASS (Table I). The rheumatologists who received the questionnaire were asked to specify how many rheumatologists they had trained and assessed according to the EFSUMB COMPASS.

\section{Results}

Of the 43 rheumatologists who were sent the questionnaire, 20 rheumatologists (46.5\%) from 14 countries responded (i.e. Austria, Belgium, Denmark, France, Germany, Hungary, Ireland, Italy, Norway, Romania, Spain, Switzerland, The Netherlands and United Kingdom. Seventeen (85\%) rheumatologists considered the EFSUMB COMPASS useful for training MSUS in their country or region. Also, the majority of those who responded (17; $85 \%$ ) had the opportunity to inform their colleagues or national rheumatology societies about the EFSUMB COMPASS. However, only in 2 countries had the national rheumatology society endorsed the COMPASS.

The most common barriers for the implementation of the COMPASS were the "lack of time for supervision of the trainees" $(9 ; 45 \%)$, "lack of financial support" (7; $35 \%$ ); "lack of support from the rheumatology society/ other specialities" (7; 35\%) and "lack of recognition by the national authorities" (7; 35\%).

Likewise, the most common problems when not implementing the COMPASS were: "alternative national competency assessment, other than EFSUMB" (7; 35\%); "lack of financial support" $(6 ; 30 \%)$; "lack of recognition by the national authorities" $(5 ; 25 \%)$ and "lack of time for acquiring the images" $(5 ; 25 \%)$. But no one answered "lack of clinical relevance".

Reportedly, a total of 83 rheumatologists had been trained and assessed for competency for the three EFSUMB levels (27 as level 1, 51 as level 2, 5 as level 3) in $9(64 \%)$ countries (i.e. Austria, Belgium, Denmark, Hungary, Italy, Norway, Romania, Spain, and the United Kingdom. Some of the respondents could not specify the number of rheumatologists assessed or did not have evidence of these data. For Germany and Romania the US training process equivalent to levels 1 and 2 was run through national programs.

The majority of the competency assessments were performed in hospitals $(12 ; 60 \%)$ and only a few of them at a national meeting or both $(5 ; 25 \%)$. The majority of the rheumatologists were assessed only for static images or videos $(13 ; 65 \%)$ produced by themselves in their clinical practice and only a few of them were supervised by the tutor or both $(3 ; 15 \%)$.

Regarding the EFSUMB website for accessing the COMPASS, half of them found the link accessible, 2 of them accessible, but not friendly, and 7 did not find it accessible.

The majority of the suggestions were on a higher visibility of EFSUMB at the European meetings and a better communication with national societies.

\section{Discussions}

The EFSUMB COMPASS for rheumatologists was published 2 years ago aiming at optimizing and standardizing the MSUS training and competency assessment for rheumatologists across Europe. It consists of a 3 level competency assessment and includes a detailed description of theoretical and practical skills that should be acquired for each level, providing a base for a uniform assessment for MSUS in rheumatology across Europe. The purpose of this survey was to evaluate the dissemination and implementation of the COMPASS in the different European countries.

A previous survey about the state of MSUS across Europe published in 2010 showed a high variability between countries regarding the implementation of MSUS in rheumatology and training and assessment in MSUS [5]. This survey reported a low number of rheumatologists and centers routinely performing MSUS (in less than $50 \%$ of countries) [5]. Regarding the education on MSUS, the training curriculum was obligatory in $22 \%$ of countries and optional in 35\% of countries. National rheumatology societies offered courses on MSUS in $40 \%$ of countries. However, this survey showed an insufficient competency assessment for MSUS in rheumatology. MSUS competency in rheumatology curriculum was assessed in only $19 \%$ of countries and MSUS competency in national rheumatology societies was assessed in only $20 \%$ of countries. Yet the survey noticed an increasingnumber of countries in which MSUS was routinely used compared with other previous surveys [5] and so rising need for training and assessment in MSUS in rheumatology. 
Table I. The questionnaire for the evaluation of EFSUMB COMPASS

\begin{tabular}{|c|c|}
\hline $\begin{array}{l}\text { 1. Have you had the opportunity to inform your col- } \\
\text { leagues/national rheumatology society about the } \\
\text { EFSUMB COMPASS? }\end{array}$ & $\begin{array}{l}\text { Yes - how } \\
\text { No - why }\end{array}$ \\
\hline $\begin{array}{l}\text { 2. Has your national rheumatology society endorsed the } \\
\text { COMPASS? }\end{array}$ & $\begin{array}{l}\text { Yes } \\
\text { No - why }\end{array}$ \\
\hline $\begin{array}{l}\text { 3. Do you find the COMPASS useful for training ultra- } \\
\text { sonography in your country/region? }\end{array}$ & $\begin{array}{l}\text { Yes - comments } \\
\text { No - why }\end{array}$ \\
\hline $\begin{array}{l}\text { 4. How many rheumatologists have been trained and as- } \\
\text { sessed as level } 1 \text { since the introduction of COMPASS in } \\
\text { your country/region? }\end{array}$ & \\
\hline $\begin{array}{l}\text { 5. How many rheumatologists have been trained and as- } \\
\text { sessed as level } 2 \text { since the introduction of COMPASS in } \\
\text { your country/region? }\end{array}$ & \\
\hline $\begin{array}{l}\text { 6. How many rheumatologists have been trained and as- } \\
\text { sessed as level } 3 \text { since the introduction of COMPASS in } \\
\text { your country/region? }\end{array}$ & \\
\hline $\begin{array}{l}\text { 7. Was the competency assessment performed at the de- } \\
\text { partment at the hospital or in national meetings ? }\end{array}$ & $\begin{array}{l}\text { Hospital } \\
\text { National meetings }\end{array}$ \\
\hline $\begin{array}{l}\text { 8. Do you supervise in person all the scans or do you } \\
\text { evaluate static images/video clips for the assessment? }\end{array}$ & $\begin{array}{l}\text { Static } \\
\text { Videos }\end{array}$ \\
\hline $\begin{array}{l}\text { 9. Do you find the link to COMPASS on the EFSUMB } \\
\text { website accessible? }\end{array}$ & $\begin{array}{l}\text { Yes } \\
\text { No-why }\end{array}$ \\
\hline $\begin{array}{l}\text { 10. What are the principal barriers for enhancing the imple- } \\
\text { mentation of the COMPASS in your country/region? }\end{array}$ & $\begin{array}{l}\text { Lack of financial support } \\
\text { Lack of support from the rheumatology society/other specialities } \\
\text { Lack of recognition by the national authorities } \\
\text { Lack of interest by rheumatologists } \\
\text { Lack of time for supervision of the images/participants } \\
\text { Lack of time for acquiring the images } \\
\text { Lack of clinical relevance } \\
\text { Alternative national competency assessment than EFSUMB } \\
\text { Other }\end{array}$ \\
\hline $\begin{array}{l}\text { 11. If the COMPASS was not implemented in your country } \\
\text { what were the problems? }\end{array}$ & $\begin{array}{l}\text { Lack of financial support } \\
\text { Lack of support from the rheumatology society/other specialities } \\
\text { Lack of recognition by the national authorities } \\
\text { Lack of interest by rheumatologists } \\
\text { Lack of time for supervision of the images/participants } \\
\text { Lack of time for acquiring the images } \\
\text { Lack of clinical relevance } \\
\text { Alternative national competency assessment than EFSUMB } \\
\text { Other }\end{array}$ \\
\hline $\begin{array}{l}\text { 12. Do you have any suggestions to improve the dis- } \\
\text { semination and implementation of COMPASS in your } \\
\text { country? }\end{array}$ & \\
\hline
\end{tabular}

In the present survey the reported number of rheumatologists trained and assessed for the three EFSUMB levels was relatively small since the introduction in 2013. The main reason for this foundin this survey was the lack of time for supervision of the trainees. Additionally, it should be mentioned that only a limited number of rheumatologists were certified as level 3 initially and therefore it is expected that it will take some time to have enough trained rheumatologists that will be able to assess other colleagues. Despite possible inconveniences (e.g. lack of time) the numbers of level 2 and 3 is increasing, which could enlarge the number of rheumatologists who 
receive the training needed to obtain at least level $1 \mathrm{EF}$ SUMB competency in the future. In addition, although the majority of the initial certified level 3 rheumatologists informed their colleagues or the national rheumatology society in their country about the EFSUMB COMPASS, only a few National Societies endorsed this assessment. As the majority of the responders remarked, this may due to the presence of alternative national training programs or competency assessment for MSUS. Although in 2009 a previous survey [5] showed a low number of countries with a competency assessment for MSUS in rheumatology, it possibly has risen over the last years. In order to make possible MSUS competency assessment and certification at both, national and international level, we suggest that a closer collaboration between MSUS education providers at European and national level and a better promotion of the EFSUMB COMPASS among the National Societies of Rheumatology using appropriate media would increase the number of rheumatologists who can be certified at the European level.

In the last years increased evidence of the MSUS role in rheumatology in both clinical and research areas has been noticed. Also since the last survey [5], the European league Against Rheumatism (EULAR) published new recommendations for the use of imaging in rheumatology in which MSUS has an important role [6-8]. Thus, a lack of interest from rheumatologists in MSUS training and assessment is unlikely. By contrast, it is assumed an increased need for a standardized competency assessment.

EULAR provides several courses in different rheumatology fields, including multiple annual courses in MSUS. Rheumatologists have also the possibility to attend EULAR endorsed MSUS courses in several European countries. Recently, EULAR has developed a Competency Assessment system in MSUS [9] consisting of 2 levels of competency (i.e. level 1 and level 2). Both EFSUMB COMPASS and EULAR Competency Assessment system have similar requirements on MSUS knowledge and skills. The theoretical and practical content of both systems were based on the previously published Recommendations for the content and conduct of EULAR MSUS Courses [3]. For the EULAR MSUS certification, the trainees must attend EULAR MSUS courses, produce a number of MSUS images that should be approved by the Faculty, and pass a final practical exam. This represents another essential step forward for a homogeneous education in MSUS across Europe. In fact, the EFSUMB COMPASS for rheumatologists and the EULAR Competency Assessment system are complementary. The MSUS EULAR courses fulfill the EFSUMB requirements as do courses from other specialties such as radiology and the supervised images required by
EFSUMB can also be used to obtain the EULAR requirements for courses.

Although the EFSUMB competency system was developed for all rheumatologists performing or interested in performing MSUS, it stands to reason that this effort is aimed primarily at the younger generations of rheumatologists. The interest of young rheumatologists in international exchange and European training has increased $[10,11]$. In this setting, The Emerging EULAR Network (EMEUNET) has become a suitable means of communication, enabling young rheumatologists in Europe to stay in touch and to be up-to-date. This communication channel could also increase awareness regarding training and competency assessment in MSUS.

An important limitation of our results is the fact that only about half of all the first levels 3 rheumatologists answered the questionnaire, with the chance to get answers only from the most involved rheumatologists in EFSUMB COMPASS.

In conclusion, this survey illustrates the current implementation of EFSUMB COMPASS in European countries with an expected increased number of rheumatologists being able to train and assess new trainees. More efforts should be done for a higher implementation of EFSUMB COMPASS across all European countries.

Disclosure statement: Esperanza Naredo has received speaker fees from Abbvie, Roche Farma, BristolMyers Squibb, Pfizer, UCB, and Novartis; Lene Terslev received speaker fees from Abbvie, Roche MSD, Pfizer and UCB; Hilde Berner Hammer received speaker fees from AbbVie, Roche, MSD, Pfizer, BMS and UCB).

\section{Conflict of interest: none}

\section{References}

1. EFSUMB. Guidelines and Recommendation in Elastography. Ultraschall Med 2012; 33: 499.

2. http://www.efsumb.org/guidelines/guidelines01.asp

3. Naredo E, Bijlsma JW, Conaghan PG, et al. Recommendations for the content and conduct of European League Against Rheumatism (EULAR) musculoskeletal ultrasound courses. Ann Rheum Dis 2008; 67: 1017-1022.

4. Terslev L, Hammer HB, Torp-Pedersen S, et al. EFSUMB minimum training requirements for rheumatologists performing musculoskeletal ultrasound. Ultraschall Med 2013; 34: 475-477.

5. Naredo E, D'Agostino MA, Conaghan PG, et al. Current state of musculoskeletal ultrasound training and implementation in Europe: results of a survey of experts and scientific societies. Rheumatology (Oxford) 2010; 49: 2438-2443. 
EFSUMB COMPASS for Rheumatologists dissemination and implementation...

6. Colebatch AN, Edwards CJ, Østergaard M, et al. EULAR recommendations for the use of imaging of the joints in the clinical management of rheumatoid arthritis. Ann Rheum Dis 2013; 72: 804-814.

7. Mandl P, Navarro-Compán V, Terslev L, et al. EULAR recommendations for the use of imaging in the diagnosis and management of spondyloarthritis in clinical practice. Ann Rheum Dis 2015; 74: 1327-1339.

8. Colebatch-Bourn AN, Edwards CJ, Collado P, et al. EULAR-PReS points to consider for the use of imaging in the diagnosis and management of juvenile idiopathic arthritis in clinical practice. Ann Rheum Dis 2015; 74: 1946-1957.

9. http://www.eular.org

10. Gaujoux-Viala C, Knevel R, Mandl P, et al. Who are the young professionals working in the field of rheumatology in Europe and what are their needs? An EMEUNET (EMerging EUlar NETwork) survey. Ann Rheum Dis 2012; 71: 1432-1433.

11. Bandinelli F, Bijlsma JW, Ramiro MS, et al. Rheumatology education in Europe: results of a survey of young rheumatologists. Clin Exp Rheumatol 2011; 29: 843-845. 